\title{
Photoperiodic Flowering Response of Essential Oil, Grain, and Fiber Hemp (Cannabis sativa L.) Cultivars
}

1 Mengzi Zhang ${ }^{1}$, Steven L. Anderson ${ }^{1}$, Zachary Brym², and Brian J. Pearson ${ }^{\text {** }}$

${ }^{1}$ Mid-Florida Research and Education Center, Department of Environmental Horticulture, Institute of

3 Food and Agricultural Sciences, University of Florida, Apopka, Florida, USA

${ }^{2}$ Tropical Research and Education Center, Department of Agronomy, Institute of Food and

Agricultural Sciences, University of Florida, Homestead, Florida, USA

* Correspondence:

7 Brian Pearson

8 bpearson@ufl.edu

9 Keywords: critical photoperiod, twilight, subtropical, cultivar, extension growth, genetic

10 variation, origin, monecious

\section{Abstract}

12 Cultivation of hemp (Cannabis sativa L.) in tropical and subtropical regions can be challenging if 13 flowering behavior of a given cultivar is unknown, poorly understood, or not accurately selected for the photoperiod. Identifying cultivars adapted to local environmental conditions is key to optimizing hemp vegetative and flowering performance. We investigated the effects of varying light cycles in regulating extension growth and flowering response of 15 essential oil and 12 fiber/grain hemp cultivars both in indoors and outdoors. Plants were subjected to eleven photoperiods in the controlled rooms ranging from $12 \mathrm{~h}$ to $18 \mathrm{~h}$, and natural day length in the field. The critical photoperiod threshold was identified for seven essential oil cultivars and two fiber/grain cultivars. 'Cherry WineCC', 'PUMA-3', and 'PUMA-4' had the shortest critical day length between $13 \mathrm{~h} 45$ min and $14 \mathrm{~h}$. The flowering of essential oil cultivars was generally delayed by 1 to $2 \mathrm{~d}$ when photoperiod exceeded $13 \mathrm{~h}$ compared to $12 \mathrm{~h}$, and flowering was further delayed by 7 to $8 \mathrm{~d}$ when photoperiod exceed $14 \mathrm{~h}$. In fiber/grain cultivars, flowering was generally delayed by 1 to $3 \mathrm{~d}$ when day length exceeded $14 \mathrm{~h}$. Flowering for most essential oil cultivars was delayed by 5 to $13 \mathrm{~d}$ under $14 \mathrm{~h}$ photoperiod compared to $13 \mathrm{~h} 45 \mathrm{~min}$, suggesting a photoperiod difference as little as $15 \mathrm{~min}$ can significantly influence the floral initiation of some essential oil cultivars. Cultivars represented by the same name but acquired from different sources can perform differently under the same environmental conditions, suggesting genetic variation among cultivars with the same name. Average days to flower of fiber/grain cultivars was correlated with reported cultivar origin with faster flowering occurring among northern cultivars when compared to southern cultivars. Plant height generally increased as the day length increased in essential oil cultivars but was not affected in fiber/grain cultivars. In addition, civil twilight of approximately $2 \mu \mathrm{mol} \cdot \mathrm{m}^{-2} \cdot \mathrm{s}^{-1}$ was discovered to be biologically effective in regulating hemp flowering. Collectively, we conclude that most of the essential oil cultivars and some southern fiber/grain cultivars tested express suitable photoperiods for tropical and sub-tropical region cultivation. 
Cultivation of hemp (Cannabis sativa L.) within the U.S. was restricted in 1937 following passage of the Marihuana Tax Act. Similarly, hemp cultivation was prohibited throughout the western world during most of the 20th century (Cherney and Small, 2016; Congressional Research Service, 2019). With the legal status of Cannabis production shifting in the U.S. following passage of the 2014 and 2018 farm bills (Agricultural Act of 2014, P.L. 113-79; Agriculture Improvement Act of 2018, P.L. 115-334), restrictions on hemp production were relaxed and interest in hemp cultivation thereafter rapidly increased. Within the U.S., classification of Cannabis is based upon the concentration of $\Delta 9$ tetrahydrocannabinol (THC) present in plant tissue. Plants with a concentration of $\leq 0.3 \%$ THC on a dry weight basis are legally recognized as industrial hemp whereas plants containing $>0.3 \%$ are recognized as marijuana, a Schedule I drug as defined by the Controlled Substances Act of 1967 (Congressional Research Service, 2019). Industrial hemp is commercially cultivated for its fiber, seed, and secondary metabolites. Hemp is used to produce a wide variety of industrial and consumer products to include food and beverages, personal care products, nutritional supplements, therapeutic products, fabrics and paper, and construction materials (Congressional Research Service, 2019). In 2016, the global fiber hemp market was valued at nearly $\$ 700$ million with an expected growth rate of $10-20 \%$, whereas the hemp-derived cannabidiol (CBD) market in 2022 is expected to be more than two-fold greater than it was in 2018 to become a $\$ 1.3$ billion-dollar market (Anderson et al., 2019; Hemp Business Journal, 2018).

Hemp can be challenging to cultivate in tropical and subtropical regions given high temperatures, high humidity, and ample presence of disease and pests. Relatively short daylengths experienced in tropical and subtropical environments, however, arguably present the greatest challenge to the successful cultivation of hemp at lower latitudes. Hemp is considered an annual, dioecious, short-day plant (SDP) originating from temperate regions of Central Asia. Most hemp varieties are photoperiodic and thus flowering of hemp is dependent upon day length or photoperiod. Cannabis has adapted to a wide range of climates and latitudes $\left(23\right.$ to $\left.52^{\circ} \mathrm{N}\right)$ and thus can possess large variability in its sensitivity to day length (Zhang et al., 2018). Timing of transition from vegetative growth to flowering is key for high yield and acceptable fiber quality of hemp (Amaducci et al., 2012). Earlier seasonal planting under critical daylength can extend the vegetative growth period prior to late-summer flowering, which is expected to occur generally 4 to 5 weeks after summer solstice in the northern hemisphere, dependent upon hemp variety and latitude (Anderson et al., 2019; Cherney and Small, 2016). Relatively short day length experienced in tropical and subtropical regions result in reduced vegetative growth and early seasonal transition to flowering that ultimately limits stem elongation and fiber biomass yield, key factors for successful commercial cultivation of industrial hemp (Cosentino et al., 2012; Hall et al., 2014). Thus, genotypes of hemp adapted to higher latitudes would be expected to perform poorly when cultivated in tropical and subtropical environments due to premature flowering and the negative influence it has on plant growth and yield (Amaducci et al., 2008; Cosentino et al., 2012; Hall et al., 2012).

Hemp expresses broad genetic diversity in hemp photoperiod requirements for vegetative-toreproductive transition requirements, similar to that seen in other major crops (e.g. maize; Navarro, et al., 2017). Identifying plant genotypes adapted to a region's light conditions is key to the successful cultivation of photoperiod crops, such as hemp (Cho et al., 2017; Jung and Müller, 2009). Zhang et al. (2018) discovered Cannabis can be generally categorized in three northern hemispheric haplogroups distinguished by geographical location (north of $40^{\circ} \mathrm{N}, 30$ to $40^{\circ} \mathrm{N}$, and south of $30^{\circ} \mathrm{N}$ ); however, a myriad of photoperiod responses can be observed when breeding among haplogroups. Hemp selected for fiber production is generally believed to be a quantitative SDP with a relatively long photoperiod, around $14 \mathrm{~h}$ (dependent upon origin of the plant material). Excluding European varieties, the photoperiod response of most industrial hemp is poorly documented. 'Kompolti' 
85

86

87

88

89

90

91

92

93

94

95

96

97

98

99

100

101

102

103

104

105

106

107

108

109

110

111

112

113

114

115

116

117

118

119

120

121

122

123

124

125

126

127

128

129

130

(Hungarian variety) and 'Futura 77' (French variety) have an estimated maximal optimum photoperiod of 13.8 and $14 \mathrm{~h}$, respectively (Heslop-Harrison and Heslop-Harrison, 1969). An estimated photoperiod of roughly $14 \mathrm{~h}$ was identified by Amaducci et al. (2008) for five European hemp cultivars as the most important single factor controlling flowering date. Flowering was increasingly delayed at longer photoperiods, but a $24 \mathrm{~h}$ photoperiod did not prevent 'Fedrina 74' (French variety) and 'Kompolti Hybrid TC' (Hungarian variety) from flowering (Lisson et al., 2000; Van der Werf et al., 1994). A Portuguese fiber variety was reported to have a maximum optimal photoperiod of $9 \mathrm{~h}$, although the critical photoperiod is somewhere between 20 and $24 \mathrm{~h}$ (HeslopHarrison and Heslop-Harrison, 1972; Lisson et al., 2000). In contrast to European hemp, flowering of Chilean and Kentucky hemp varieties occurred promptly under a photoperiod of $14 \mathrm{~h}$ or fewer but was considerably delayed or failed to flower when photoperiod exceeded 16 hours (Borthwick and Scully, 1954). A subtropical Australian variety, 'BundyGem', had a critical photoperiod between 13 $\mathrm{h} 40 \mathrm{~min}$ and $14 \mathrm{~h} 40 \mathrm{~min}$, and plant maturity was significantly delayed when day length exceeded 14 h 40 min (Hall et al., 2014). An 11 to $12 \mathrm{~h}$ photoperiod has been reported to induce flowering of Thai hemp (Sengloung et al., 2009). While most of the studies on hemp was conducted in the field or greenhouses, plant responses to environment factors in a more strictly controlled environment, such as growth chambers, are very limited.

Until recently, Cannabis plants grown for recreational use have largely been cultivated indoors using artificial lighting. Given most of these cultivation operations were conducted prior to legalization of marijuana and were thus illegal, critical photoperiod of these types of Cannabis plants are not documented in the literature and information is limited. A day length of $12 \mathrm{~h}$ and $18 \mathrm{~h}$ are common practices to induce flowering or keep plants vegetative, respectively (Potter, 2014). Moher et al. (2020) indicated that C. sativa '802', which although is not categorized as hemp given its 15 to $20 \%$ THC content, had a critical photoperiod between 15 to 16 hours. Growth chamber environments are ideal for investigating photoperiodism of hemp. With artificial lighting (typically from light-emitting diodes) being the only radiation source indoors, photoperiod is strictly controlled by the hours of light operation. In tropical and subtropical regions, vegetation of hemp under long days can be achieved in protected environments, such as greenhouses, by manipulating photoperiod utilizing endof-day extension lighting and night interruption techniques that have been utilized in production of other common SDPs (Lane et al., 1963; Vince-Prue and Canham, 1983; Runkle et al., 1998; Zhang and Runkle, 2019). However, since hemp is often cultivated outdoors to reduce production costs, it is imperative that it is germinated or transplanted at timing with respect to natural photoperiod. Prediction of flowering time in response to a specific, known photoperiod is thus critical to support successful production both outdoors and indoors and optimization of select hemp varieties for a diverse range of growing regions. To directly address these needs, we utilized 7 growth chambers and investigated 15 cultivars of essential oil hemp and 12 cultivars of fiber/grain hemp to (i) empirically define critical photoperiod thresholds to induce vegetative to floral transition in diverse hemp cultivars, (ii) compare critical photoperiod thresholds to flowering dates within a subtropical field environment, and (iii) quantify physiological response of hemp cultivars under different photoperiod treatments.

\section{MATERIALS AND METHODS}

\section{Expt.1: Photoperiod trial for selected essential oil cultivars}

Seedling preparation and vegetative stage. Seeds, cuttings, or plants of all essential oil cultivars were obtained from three different sources (Supplementary table 1). Cultivars were selected based upon commercial interest and availability. Seeds of five essential oil cultivars, 'Cherry Wine-BS', 'Cherry Blossom-BS', 'Cherry*T1-BS', 'Berry Blossom-BS', and 'Cherry Blossom-Tuan-BS', were sown in 
72 round cell propagation sheets (DPS72, The HC Companies, Twinsburg, OH) within Pro-Mix soilless substrate (HP Mycorrhizae Pro-Mix; Premier Tech Horticulture Ltd., Quakertown, PA, United States) containing $65-75 \%$ peat, $8-35 \%$ perlite, dolomite limestone, and mycorrhizae on November 19, 2019. Cuttings of the other 10 essential oil cultivars, 'ACDC-AC', 'Super CBD-AC', 'Cherry-AC', 'Wife-AC', 'Cherry Blossom-BC', 'JL Baux-CC', 'ACDC-CC', 'Cherry Wine-CC', 'Cherry-CC', and 'Wife-CC', were propagated on November 25, 2019. Each cultivar was propagated from identical mother stock plants to reduce potential genetic diversity among replicates. Stems of plant propagules were dipped into rooting hormone (Dip'N Grow; Dip'N Grow Inc., Clackamas, OR, United States) containing 1000 ppm indole-3-butyric acid (IBA) / 500 ppm napthaleneacetic acid (NAA) and then inserted into $3.8 \mathrm{~cm}$ rockwool cubes (Grodan; ROXUL Inc., Milton, Canada) that were pre-soaked with water containing a $\mathrm{pH}$ of 5.8 as per manufacturer recommendations. Both seeded trays and cuttings were grown at $25 \square$ under $24 \mathrm{~h}$ photoperiod and were hand irrigated daily as needed.

144 After roots were well established ( $21 \mathrm{~d})$, the most uniform rooted propagules of each cultivar were selected and transplanted into 1.1 L containers (SVD-450, T.O. Plastics, Clearwater, MN, U.S.) filled with Pro-Mix soilless substrate and top-dressed with $5 \mathrm{~g}$ of Osmocote Plus 15-9-12 5-6 month slowrelease fertilizer (Everris NA, Inc.; Dublin, OH, United States) containing 7\% ammoniacal and $8 \%$ nitrate nitrogen, $9 \%$ phosphate and $12 \%$ soluble potash on December 17, 2019. Plants were randomly assigned to seven identical controlled rooms with 10 replicates per cultivar in each room and were cultivated at $25 \square$ under a photoperiod of 18 hours (0600 HR to $2400 \mathrm{HR}$ ) for vegetative growth. Plants were irrigated for 4 min every 5 days for the first two weeks and 4 min every 3 days thereafter as controlled by an automatic irrigation system.

153 Lighting treatments during flowering stage. After three weeks of vegetative growth following 154 transplant, seven lighting treatments were randomly assigned to each controlled room on January 7 , 2020. Ten plants of each hemp cultivar were grown at $25 \square$ under the photoperiod of $12 \mathrm{~h}(0600 \mathrm{HR}$ to $1800 \mathrm{HR}), 12 \mathrm{~h} 30 \mathrm{~min}$ (0600 HR to $1830 \mathrm{HR}), 13 \mathrm{~h}(0600 \mathrm{HR}$ to $1900 \mathrm{HR}), 13 \mathrm{~h} 30 \mathrm{~min}(0600 \mathrm{HR}$ to $1930 \mathrm{HR}$ ), $13 \mathrm{~h} 45 \mathrm{~min}$ (0600 HR to $1945 \mathrm{HR}$ ), $14 \mathrm{~h}$ (0600 HR to $2000 \mathrm{HR}$ ), and $18 \mathrm{~h}$ (0600 HR to 2400 HR) provided by light-emitting diodes (LEDs) (VYPR 2p; Fluence Bioengineering, Inc., Austin, TX, United States). Lighting treatments were maintained until termination of the experiment five weeks following the vegetative growth period.

Environmental conditions during seedling, vegetative, and flowering stage. Propagation of cuttings and germination of seeds was conducted indoors in an environmentally controlled propagation room at the Mid-Florida Research and Education Center (Apopka, FL, United States). Air temperatures were maintained in all indoor grow rooms utilizing air conditioners set to $25 \square$. Air temperature and relative humidity data was collected every 10 minutes by thermocouples installed at plant canopy height and data was recorded utilizing a wireless data logging station (HOBO RX3000; Onset Computer Corporation, Bourne, MA, United States) every 10 minutes. The average temperature in the propagation room was $24.9 \pm 0.04 \square$. Within the propagation room, $24 \mathrm{~h}$ photoperiod was provided by fluorescent lamps (E-conolight; Sturtevant, WI, United States) as sole-source lighting. The photosynthetic photon flux density (PPFD) on the propagation bench was measured by a quantum sensor (MQ-500; Apogee Instruments Inc., Logan, UT, United States) at 10 representative positions at the seedling canopy level. Average PPFD that cuttings and seedlings received was $53.9 \pm$ 3.02 and $73.5 \pm 3.61 \mu \mathrm{mol} \cdot \mathrm{m}^{-2} \cdot \mathrm{s}^{-1}$, respectively, with a daily light integral of approximately 4.7 and $6.4 \mathrm{~mol} \cdot \mathrm{m}^{-2} \cdot \mathrm{d}^{-1}$, respectively.

Following transplant, all plants were cultivated in seven identical environmentally controlled rooms. Each room was equipped with two sole-source LEDs (VYPR 2p; Fluence Bioengineering, Inc., Austin, TX, United States) regulated by a timer (Titan Controls Apollo 8; Hawthorne Gardening 
Company, Vancouver, WA, United States) to provide varying controlled photoperiod treatments. A PPFD of approximately 300 and $330 \mu \mathrm{mol} \cdot \mathrm{m}^{-2} \cdot \mathrm{s}^{-1}$ was maintained at plant canopy height at the onset of the vegetative stage and flowering stage, respectively. Average temperature, relative humidity, and light intensity for vegetative and flowering stages for each lighting treatment are reported in Supplementary table 2 .

Plant measurements and data collection. Flowering of female hemp plants is defined as the appearance of dual, fork-shaped stigmas protruding from tubular bracts (Hall et al., 2012) being visible at the apical meristem or decimal code of 2201 defined by Mediavilla et al., (1998). Flowering of male hemp plants is defined when five radial segments of the first pointed male bud open and start to release pollen (Hall et al., 2012) or decimal code of 2101 (Mediavilla et al., 1998). Plant height (from the substrate surface to the tallest meristem) was measured at the initiation of lighting treatments and at flowering. Extension growth was calculated by subtracting initial plant height from height at flowering. Days to flower and plant sex were recorded when plants initiated flowering. Boolean evaluation of plant flowering status was conducted at the end of week 5 following initiation of lighting treatments.

Experimental design and data analysis. The experiment was conducted using a complete randomized design with seven lighting treatments and multiple replicates. Each plant was considered an experimental unit. Data were pooled from multiple replicates and were analyzed with a restricted maximum likelihood mixed model analysis in JMP ${ }^{\circledR}$ Pro 15 (SAS Institute, Inc., Cary, NC, United States) with post-hoc mean separation tests performed using Tukey's honest significant difference test at $P \leq 0.05$.

\section{Expt.2: Photoperiod trial for fiber and grain cultivars}

Seedling preparation and vegetative stage. Twelve fiber/grain hemp cultivars from six different source origins were purchased, including Canadian cultivars - 'CFX-1' and 'Joey'; Polish cultivar 'Tygra'; Southern European cultivars - 'Carmagnola Selezionata', 'Helena', 'Fibranova', and 'Eletta Campana'; Northern Chinese cultivar - 'HAN-FN-H'; Central Chinese cultivars - 'HAN-NE' and 'HAN-NW'; and Southern Chinese cultivars - 'PUMA-3' and 'PUMA-4'. Seeds were sown in a 72 round cell propagation sheets (DPS72, The HC Companies, Twinsburg, OH) filled with Pro-Mix HP soilless substrate on February 18, 2020. They were placed under a mist bench in a greenhouse and grown at $25 \square$ under natural daylight supplemented with $1000 \mathrm{~W}$ metal halide lighting to maintain an $18 \mathrm{~h}$ photoperiod. Seedlings were misted for $1 \mathrm{~min}$ at $8 \mathrm{am}, 12 \mathrm{pm}$, and $5 \mathrm{pm}$ each day.

Seedlings possessing the most uniform height were selected three weeks after germination when roots were well established and transplanted into 1.1 L containers, as described above, with Fafard 4P potting media (Sun Gro Horticulture Canada Ltd., Agawam, MA, United States) containing 48\% peat, $30 \%$ pine bark, $10 \%$ perlite, and $12 \%$ vermiculite,top-dressed with $5 \mathrm{~g}$ of Osmocote Plus slowrelease fertilizer as described above. Plants were randomly assigned to seven identical environmentally controlled rooms with 10 replicates for 'CFX-1', 'Tygra', 'Helena', 'Eletta Campana', 'HAN-FN-H', and 'HAN-NE'; 9 replicates for 'PUMA-3'; 7 replicates for 'Joey' and 'Fibranova'; replicates for 'PUMA-4'; 4 replicates for 'Carmagnola Selezionata' and 'HAN-NW' due to poor germination rates. Plants were grown at $25 \square$ under $18 \mathrm{~h}$ photoperiod (0600 HR to 2400 $\mathrm{HR}$ ) for vegetative growth until initiation of photoperiod treatments.

Lighting treatments during flowering stage. Seven lighting treatments were randomly assigned to each controlled room after two weeks of plant vegetative growth on March 23, 2020. Twelve fiber/grain hemp cultivars were subjected to seven photoperiod treatments: $12 \mathrm{~h}$ (0600 HR to 1800 HR), 13 h $30 \mathrm{~min}$ (0600 HR to $1930 \mathrm{HR}$ ), 13 h $45 \mathrm{~min}$ (0600 HR to $1945 \mathrm{HR}$ ), 14 h (0600 HR to 2000 
HR), $14 \mathrm{~h} 30 \mathrm{~min}$ (0600 HR to $2030 \mathrm{HR}$ ), $14 \mathrm{~h} 45 \mathrm{~min}$ (0600 HR to $2045 \mathrm{HR}$ ), and $18 \mathrm{~h}$ (0600 HR to $2400 \mathrm{HR}$ ) provided by LEDs. Treatments were selected based on the common photoperiod range of fiber/grain cultivars documented in literature and the expected photoperiod of tropical and subtropical regions. Lighting treatments were maintained for five weeks before the termination of the

228 experiment.

Environmental conditions during seedling, vegetative, and flowering stage. Germination of seedlings

230

231 was conducted in a research greenhouse under a mist bench. Greenhouse heaters and fans were controlled by an environmental control system (Wadsworth Control System, Arvada, CO, United States) and set to operate when greenhouse temperature was $\leq 16 \square$ or $\geq 24 \square$, respectively. Seedlings were misted for a duration of $1 \mathrm{~min}$ three times per day utilizing a programmable irrigation controller (Sterling 12; Superior Controls Co., Inc., Valencia, CA, United States) and subjected to an $18 \mathrm{~h}$ photoperiod (from $0700 \mathrm{HR}$ to $0100 \mathrm{HR}$ ) with $11 \mathrm{~h}$ of ambient solar radiation (from $0700 \mathrm{HR}$ to $1800 \mathrm{HR}$ ) and $8 \mathrm{~h}$ of supplemental metal halide $7500{ }^{\circ} \mathrm{K}$ lamps (UltraSun $1000 \mathrm{~W}$; Hawthorne Hydroponics LLC., Vancouver, WA, United States) that operated from $1700 \mathrm{HR}$ to $0100 \mathrm{HR}$. Greenhouse environmental conditions were recorded every $15 \mathrm{~min}$ by a weather station data logger (WatchDog 2475; Spectrum Technologies, Inc., Aurora, IL, United States). Average air temperature, relative humidity, photosynthetic active radiation, and DLI was $24.0 \pm 0.08 \square, 60.1 \pm 0.45 \%, 261.6$ $\pm 5.07 \mu \mathrm{mol} \cdot \mathrm{m}^{-2} \cdot \mathrm{s}^{-1}$, and $22.6 \pm 0.44 \mathrm{~mol} \cdot \mathrm{m}^{-2} \cdot \mathrm{d}^{-1}$, respectively.

After transplant in $1.1 \mathrm{~L}$ containers, all plants were cultivated in seven identical environmentally controlled rooms, as described previously. Average air temperature, relative humidity, and light intensity for the vegetative stage and flowering stage for each lighting treatment were also reported in Supplementary table 2.

Plant measurements and data collection. Plant height, recorded from the substrate surface to the tallest meristem, was measured at initiation of lighting treatments and at flowering. Days to flower and plant sex were recorded when plants started to flower, as defined previously. Flowering of monecious plants was defined when female or male flowering occurred as defined previously or by decimal code of 2301 and 2304, respectively (Mediavilla et al., 1998). Boolean evaluation of plant flowering status was conducted at the end of week 5 after the initiation of the lighting treatments. Experimental design and data analysis were conducted as described for Expt. 1.

253

\section{Expt.3: Expanded photoperiod trial for selected essential oil and fiber/grain cultivars}

Based on results of Expt. 1 and 2., an expanded photoperiod trial was designed with select essential oil, fiber, and grain cultivars to better understand the effect of photoperiodism on a broader scale.

Seedling preparation and vegetative stage. Six fiber/grain hemp cultivars, 'Carmagnola Selezionata', 'Helena', 'Eletta Campana', 'HAN-FN-H', 'PUMA-3', and 'PUMA-4', were propagated as described in Expt.2 on May 24, 2020. Cuttings of 10 essential oil cultivars, 'ACDC-AC', 'Super CBD-AC', 'Cherry-AC', 'Cherry Blossom-BC', 'Cherry Wine-BS', 'Cherry Blossom-BS', 'Cherry*T1-BS', 'JL Baux-CC', 'ACDC-CC', and 'Cherry-CC', were propagated as described in Expt. 1 on June 18, 2020. Both cuttings and seeded trays were placed under a mist bench that misted 8 s every $20 \mathrm{~min}$ in a greenhouse and grown at $25 \square$ under natural daylight with supplemental metal halide lamps as described in Expt. 2 maintaining an $18 \mathrm{~h}$ photoperiod. Plants grew vegetatively under the mist bench in the greenhouse for 3-4 weeks before being transplanted into $1.1 \mathrm{~L}$ containers and assigned to lighting treatments.

267 Seedlings or clones of the 10 essential oil cultivars were thinned and transplanted as described in 268 Expt. 2 with Pro-Mix HP soilless substrate on June 18, 2020, for fiber cultivars, and July 11, 2020, 
for essential oil cultivars. Slow-release fertilizer was applied as described in Expt. 1. All plants were cultivated for vegetative growth for $7 \mathrm{~d}$ and then randomly assigned to identical environmentally controlled rooms under different lighting treatments with 5 replicates per each cultivar.

Lighting treatments during flowering stage. Six lighting treatments were randomly assigned to each controlled room as proposed: $12 \mathrm{~h} 30 \mathrm{~min}$ (0600 HR to $1830 \mathrm{HR}$ ), $13 \mathrm{~h} \mathrm{(0600} \mathrm{HR} \mathrm{to} 1900 \mathrm{HR}$ ), $14 \mathrm{~h} 30$ min (0600 HR to $2030 \mathrm{HR}), 14 \mathrm{~h} 45 \mathrm{~min}$ (0600 HR to $2045 \mathrm{HR}), 15 \mathrm{~h}$ (0600 HR to $2100 \mathrm{HR}$ ), and $15 \mathrm{~h}$ $30 \mathrm{~min}$ (0600 HR to $2130 \mathrm{HR}$ ). Different photoperiods were provided by LEDs as described previously. Photoperiod lighting treatments were maintained for five weeks before the termination of the experiment. Ten essential oil cultivars were selected based on the results from Expt. 1 and were evaluated from $14 \mathrm{~h} 30 \mathrm{~min}$ to $15 \mathrm{~h} 30 \mathrm{~min}$.

A Boolean evaluation of flowering status was conducted as described previously. Environmental conditions of the greenhouse during the vegetative stage were as described in Expt. 2 and the environmental conditions of the controlled rooms during the flowering stage were as described in Expt. 1 and provided in Supplementary table 2. Experimental design and data analysis were conducted as described for Expt. 1.

\section{Expt.4: Flowering time trial under natural daylengths within a field-grown subtropical Central} Florida environment.

Seedling preparation and vegetative stage. Fourteen essential oil and 18 fiber/grain cultivars were evaluated for flowering response time under natural daylength, field-grown conditions following seedling establishment of fiber/grain cultivars and rooting of clonally propagated essential oil cultivars. Fiber/grain seeds were sown in 72-cell trays within Pro-Mix HP soilless substrate on April 30, 2020 and propagated as described in Expt. 2. Seedlings were watered daily by hand as needed. Fourteen essential oil cultivars were clonally propagated as described in Expt. 2 on May 1, 2020. Rooted plants were transplanted into field on June 3, 2020.

Field trial set up. The field trial was designed using plasticulture production techniques with Chapin Turbulent Flow-Deluxe drip tape (Catalog \# 11714142N, Jain Irrigation USA, Watertown, NY, USA) placed below the plastic emitting $0.76 \mathrm{~L} \mathrm{~h}^{-1}$ per dripper at $68.9 \mathrm{kPa}$ spaced $0.10 \mathrm{~m}$ between drippers. Plants were spaced $0.9 \mathrm{~m}$ apart within rows and rows were spaced $1.5 \mathrm{~m}$ apart between row centers. Total plot lengths were $3.7 \mathrm{~m}$ including walking allies. Total trial area was 0.9 ha. Trials received 2 hours of drip irrigation per day. A soluble fertilizer with micronutrients (Peter 20-20-20; ICL Specialty Fertilizers, Dorchester County, SC, U.S.), was applied every $14 \mathrm{~d}$ at a rate of $8.8 \mathrm{~kg} \mathrm{~N}$ $\mathrm{ha}^{-1}$ for an accumulated rate of $48 \mathrm{~kg} \mathrm{~N} \mathrm{ha}^{-1}$ (6 applications total).

302 Experimental design and data collection. The experiment was conducted using a complete randomized block design comprised of an essential oil trial and a fiber/grain trial. Both trials contain three replicates of each cultivar. Each plot/replicate within the trial consisted of three plants. Flowering time was measured as defined previously. Light intensity during civil twilight period (sun 6 to 0 degrees below horizon) was recorded every two minutes manually in an open field with a quantum sensor (MQ-500; Apogee Instruments Inc., Logan, UT, United States) for three days. A restricted maximum likelihood mixed model analysis in $\mathrm{JMP}^{\circledR}$ Pro 15 (SAS Institute, Inc., Cary, NC, United States) was performed to estimate genetic means of flowering time. 


\section{Identifying Critical Photoperiod Thresholds}

313 Critical photoperiod differed significantly among essential oil cultivars (Table 1). In addition, a 314 significant effect was observed on flowering percentages of the essential oil cultivars. As expected, all essential oil cultivars flowered in response to $12 \mathrm{~h}$ photoperiod and no plants flowered in response to $18 \mathrm{~h}$ (Table 1). One cultivar, 'Cherry Wine-CC', was identified with a critical photoperiod below $14 \mathrm{~h}$, with no flowers developed under $14 \mathrm{~h}$. Four cultivars expressed $100 \%$ floral initiation at the longest photoperiod (14 h, excluding $18 \mathrm{~h}$ control) with an additional six cultivars that demonstrated a complete floral initiation $(>50 \%)$ when cultivated under $14 \mathrm{~h}$ of light. For this reason, expanded photoperiod treatments of up to $15 \mathrm{~h} 30$ min were evaluated for select essential oil cultivars (Expt. 3). Of the 10 essential oil cultivars evaluated within Expt. 3, five cultivars expressed a majority $(>50 \%)$ of floral initiation between $15 \mathrm{~h}$ and $15 \mathrm{~h} \mathrm{30min.} \mathrm{Four} \mathrm{of} \mathrm{them,} \mathrm{including} \mathrm{'Cherry-AC',} \mathrm{'Cherry}$ Blossom-BS', 'ACDC-CC', and 'Cherry-CC', have been identified with a critical photoperiod within this range. In addition, 'Cherry Wine-CC' had the shortest, critical photoperiod identified between 13 h $45 \mathrm{~min}$ and $14 \mathrm{~h}$. The critical photoperiod for 'Super CBD-AC' and 'Cherry Blossom-BC' occurred between $14 \mathrm{~h} 45 \mathrm{~min}$ and $15 \mathrm{~h}$. For the rest of the cultivars, 'ACDC-AC' had a significant flowering reduction when the photoperiod was extended from $15 \mathrm{~h}$ to $15 \mathrm{~h} \mathrm{30min.} \mathrm{'Wife-AC'} \mathrm{flowered}$ significantly less under $13 \mathrm{~h} 30 \mathrm{~min}$ compared to $13 \mathrm{~h}$, but the critical photoperiod is likely greater than $14 \mathrm{~h}$. Similarly, the percentage flowering of 'Berry Blossom-BS', 'Cherry Blossom-Tuan-BS', and 'Wife-CC' decreased when photoperiod was increased from $13 \mathrm{~h} 45 \mathrm{~min}$ to $14 \mathrm{~h}$. Our results suggest that a photoperiod difference as little as 15 min could have a significant influence on floral initiation and development of some essential oil hemp cultivars. Moreover, floral initiation can occur at varying rates when the photoperiod is close to the critical threshold of some cultivars.

Less variation in critical photoperiod thresholds were observed for fiber/grain hemp than essential oil cultivars. Similar to essential oil cultivars, all fiber/grain cultivars flowered in response to $12 \mathrm{~h}$ photoperiod (Table 1). For the majority of the fiber cultivars (8 of 12), plants did not flower under an $18 \mathrm{~h}$ photoperiod. 'CFX-1', 'Joey', 'Tygra', and 'Helena' flowered in response to a photoperiod of $18 \mathrm{~h}$ and did not remain vegetative like the majority of the other fiber hemp cultivars evaluated in this study, thus suggesting their critical photoperiod could be above $18 \mathrm{~h}$. The critical photoperiod of PUMA 3 and 4 was identified between $13 \mathrm{~h} 45 \mathrm{~min}$ and $14 \mathrm{~h}$, but the floral initiation was greatly reduced by more than $70 \%$ when day length exceeded $13 \mathrm{~h}$. Similarly, the flowering of HAN-NE and HAN-NW was also greatly reduced when day length exceeded $14 \mathrm{~h} 30 \mathrm{~min}$. To verify the critical photoperiod of 'CFX-1', 'Joey', 'Tygra', and 'Helena', seeds were germinated on February 18, 2020, and placed under $24 \mathrm{~h}$ photoperiod in a greenhouse. All four cultivars flowered on April 20, 2020 under a $24 \mathrm{~h}$ photoperiod. This observation was consistent with previous reports where $24 \mathrm{~h}$ photoperiod did not prevent the flowering of 'Fedrina 74' and 'Kompolti Hybrid TC' and that the critical photoperiod of a Portuguese fiber hemp variety from Coimbra is between 20 and $24 \mathrm{~h}$ (Heslop-Harrison and Heslop-Harrison, 1972; Van der Werf et al., 1994). In addition, 'CFX-1' and 'Joey' formed flower buds during the three-week propagation stage in the greenhouse in Expt. 2. Available literature supports that primordium formation in hemp varieties occurs in response to quantitative short days and the photoperiod inductive phase is jointly affected by photoperiod and temperature (Lisson et al., 2000; Hall et al., 2012). However, Spitzer-Rimon et al. (2019) argued that Cannabis can enter the reproductive phase under both long-day and short-day conditions because "solitary flowers", which being developed in the axil of each stipulate leaf, are differentiated under such conditions, and flower induction of "solitary flowers" is likely age-dependent and is controlled not by photoperiod, but rather internal signals. Therefore, they reported that Cannabis can be considered a day-neutral plant where floral initiation is not dependent upon photoperiod requirements. These "solitary flowers", which can be referred to as sex-indicating flowers or pre- 
flowers, are believed to be the start of calyx development in hemp and are not photoperiod dependent (Green 2017; Williams, 2020). In our study, long-day conditions did not prevent the floral initiation of 'CFX-1', 'Joey', 'Tygra', and 'Helena'. Thus, they are likely day-neutral cultivars given floral initiation occurred in response to $24 \mathrm{~h}$ photoperiod.

363 Hall et al. (2012) suggested that the hemp juvenile phase was not affected by photoperiod and the length of the juvenile phase is either determined by development of reproductive organs or the apical meristem, which is independently timed to produce flowering signals. In our study, the length of juvenile phase was observed to be cultivar specific, with 'CFX-1' being the shortest and 'Helena' being the longest among the four, day-neutral cultivars (Fig 2). Traits, such as days to maturity and cannabinoid production, have been identified to be nearly entirely controlled by genetics. However, environment can play a significant role for other traits, such as yield and plant height, and thus the influence of environment and genetics are likely needed to be considered collectively (Campbell et al., 2019). Different hemp cultivars have been suggested to have different lengths of juvenile phase and photo-sensitive phase largely in association with geographic origin. Cultivars adapted to northern latitudes tend to have a short life cycle and grow and flower faster within their limited growing seasons, whereas cultivars adapted to southern latitudes and closer to the equator tend to flower later to ensure sufficient vegetative growth before short days occur (Amaducci et al., 2008; Small, 2015; Zhang et al., 2018). This theory is supported by our study results where cultivars of northern origin ('CFX', 'Joey', 'Tygra', etc.) responded to a longer photoperiod and flowered faster than southern cultivars ('PUMA-3', 'PUMA-4', 'HAN-NW', etc.) having a shorter critical day length threshold (Fig 2). Thus, understanding the juvenile phase and photosensitivity is essential for selecting the right hemp cultivar for a target region.

Some plant species can respond to light even at a very low intensity and are thus considered highly photosensitive. For these species of plants, civil twilight, or the period of time that occurs shortly before sunrise and after sunset when the sun is between 0 and 6 degrees below the horizon, may still be biologically effective to the plant's photoperiodism response (Kishida, 1989; Salisbury, 1981). For example, rice (Oryza sativa) is light-insensitive to twilight both at dusk and dawn; perilla (Perilla frutescens) and Biloxi soybean (Glycine max) are light-insensitive at dusk but more light-sensitive at dawn; and cocklebur (Xanthium saccharatum) is both light-sensitive at dusk and dawn (Takimoto and Ikeda, 1961). For hemp, Borthwick and Scully (1954) suggested that 0.12 foot-candle or more would sufficiently prevent hemp from flowering, suggesting hemp is rather sensitive to light. In our experience, light intensity as little as $2 \mu \mathrm{mol} \cdot \mathrm{m}^{-2} \cdot \mathrm{s}^{-1}$ can cause light pollution and disrupt vegetative growth and transition hemp into flowering for 'Cherry Blossom-BS' in the greenhouse. To evaluate the effect of twilight on hemp, we conducted field trials (Expt. 4) to investigate the performance of essential oil, fiber, and grain hemp cultivars under natural day light conditions. The average light intensity during civil twilight period in our study was $2.4 \pm 0.54 \mu \mathrm{mol} \cdot \mathrm{m}^{-2} \cdot \mathrm{s}^{-1}$, which is within the light range reported by Kishida (1989). By comparing plant response and photoperiod to sunrise to sunset daylengths and civil twilight lengths, we concluded that flowering performance of hemp is affected by civil twilight (Fig. 1). Most flowering data from the field trial was in alignment with our trials from the controlled rooms (Expt. 1 to 3) and plants flowered within the critical photoperiod we tested, with only a few exceptions. 'JL Baux-CC' and 'ACDC-AC' flowered later and slower in the field compared to the controlled rooms (Fig. 1). It is possible that the day length changes under the natural conditions are slower to occur and not as drastic compared to conditions imposed in the controlled rooms and therefore plants would respond to day length changes slower under natural conditions. On the contrary, 'Super CBD-AC' and 'Cherry-CC' flowered earlier, suggesting that they might be more sensitive to the dark period. In addition, differences in individuals perception of 
406

407

408

409

410

411

412

413

414

415

416

417

418

419

420

421

422

423

424

425

426

427

428

429

430

431

432

433

434

435

436

437

438

439

440

441

442

443

444

445

446

447

448 initiation dates collected for these cultivars, additional years of field trials will aid in the importance of civil twilight's effect on Cannabis flowering. Collectively, we believe that civil twilight length and the slow progression of day length changes under natural conditions should be taken into consideration for the biologically effective photoperiod for hemp flowering.

\section{Days to Flower}

Flowering response was delayed as flowering photoperiod increased. In both essential oil and fiber/grain cultivars, plants subjected to $12 \mathrm{~h}$ photoperiod had an average flowering time of 13-14 d (Fig. 2). This is supported by Borthwick and Scully (1954) where 10-14 d of short-day photoperiod was sufficient for flower induction in at least some of the Chilean and Kentucky varieties.

Among essential oil cultivars, flowering was generally delayed by 1 to $2 \mathrm{~d}$ when photoperiod exceeded $13 \mathrm{~h}$ compared to $12 \mathrm{~h}$, and flowering was significantly delayed by 7 to $8 \mathrm{~d}$ when photoperiod exceed $14 \mathrm{~h}$ (Fig. 2). Across cultivars and regardless of sources, 'ACDC' and 'Super CBD' flowered the fastest, with an average flowering time of $13 \mathrm{~d}$ after initiation of the critical photoperiod. 'Wife-AC', 'Wife-CC', and 'Cherry Wine' had an average flowering time of $21 \mathrm{~d}$, suggesting these cultivars took longer to either perceive the photoperiod or to complete flower formation and initiation.

Essential oil hemp cultivars demonstrated delayed floral initiation at longer photoperiods and significant genetic variation in floral initiation across photoperiod treatments. Variance in observed photosensitivity is likely a result of genetic variation that influenced floral initiation response to light cues. Flowering for most essential oil cultivars was delayed by 5 to $13 \mathrm{~d}$ under $14 \mathrm{~h}$ photoperiod compared to $13 \mathrm{~h} 45 \mathrm{~min}$ (Fig. 3 and Supplementary fig. 1). Flowering of 'ACDC-AC' and 'Cherry*T1-BS' was significantly delayed by 4 and $6 \mathrm{~d}$, respectively, under $13 \mathrm{~h} 45$ min compared to $12 \mathrm{~h}$. Moreover, the delayed flowering of 'Cherry-CC' started at $13 \mathrm{~h} 30 \mathrm{~min}$ and in 'Wife-CC', $13 \mathrm{~h}$. This suggests that floral initiation of these cultivars was more sensitive to photoperiod than others. In contrast, no significant differences were observed in days to flower among different treatments of 'Wife-AC', 'Berry Blossom-BS', and 'Cherry Blossom-Tuan-BS', suggesting the flowering formation and initiation were rather similar under different day lengths, as long as they were below the critical photoperiod.

Cultivars represented by the same name acquired from different sources performed differently in days to flower. A photoperiod of $13 \mathrm{~h} 30 \mathrm{~min}$ significantly delayed the flowering of 'ACDC-CC' but not 'ACDC-AC', whereas $13 \mathrm{~h} 45 \mathrm{~min}$ delayed the flowering of 'ACDC-AC' but not 'ACDC-CC' (Fig. 3). Delay of flowering in 'Cherry-CC' started under a photoperiod of $13 \mathrm{~h} 30 \mathrm{~min}$, while flowering occurred $30 \mathrm{~min}$ later at $14 \mathrm{~h}$ for 'Cherry-AC'. A photoperiod of $13 \mathrm{~h}$ delayed flowering of 'Wife-CC' by $8 \mathrm{~d}$ compared to $12 \mathrm{~h}$, but not in 'Wife-AC'. Similarly, flowering of 'Cherry Wine-BS' was significantly delayed by $7 \mathrm{~d}$ under $13 \mathrm{~h}$ photoperiod compared to $12 \mathrm{~h}$ photoperiod, but no differences in flowering were observed in 'Cherry Wine-CC'. These results, in conjunction with Sawler et al. (2015), indicated that plants with the same cultivar names from different sources could have varying genetics and subsequently performed differently.

Most fiber/grain cultivars tested did not flower under $18 \mathrm{~h}$ photoperiod (Table 1). Flowering was delayed by 1 to $3 \mathrm{~d}$ if the photoperiod exceeded $14 \mathrm{~h}$ and no differences were observed among treatments beyond $14 \mathrm{~h}$ (Fig. 2). This is consistent with the theory that hemp is a quantitative SDP and has a photoperiod of roughly $14 \mathrm{~h}$ where flowering would occur promptly below $14 \mathrm{~h}$ and 
flowering would be delayed under a longer photoperiod (Amaducci et al., 2008; Borthwick and Scully, 1954; Hall et al., 2014; Heslop-Harrison and Heslop-Harrison, 1969). When subjected to the critical photoperiod, average days to flower was shortest among cultivars from northern latitudes and longest among those from southern latitudes with a gradient response correlated to the cultivar's genetic origin. More specifically, Canadian/Northern European cultivars flowered 4 to $11 \mathrm{~d}$ after lighting transition. Cultivars from comparatively lower latitudinal regions (Northern Chinese/Southern European) flowered from 12 to $16 \mathrm{~d}$ whereas Southern Chinese cultivars flowered 21 to $25 \mathrm{~d}$ (Fig. 2 and Supplementary fig. 2). Moreover, different photoperiod treatments did not affect the flowering of 'CFX-1', 'Joey', 'Tygra', 'Carmagnola', and 'Helena' (Supplementary fig. 2). Collectively, considering that $24 \mathrm{~h}$ day length did not prevent 'CFX-1', 'Joey', 'Tygra', and 'Helena' from flowering and their flowering process was not influenced by imposed photoperiods (Table 1 and Supplementary fig. 2), these four fiber cultivars are likely photoperiod insensitive or day-neutral.

Temperature differences and other stresses such as nutrient deficiencies can result in differences in flowering time (Amaducci et al., 2008; Hall et al., 2012). Amaducci et al. (2008) indicated that high temperature will accelerate flowering by decreasing the duration between the formation of flower primordia and full flowering, and thus modeling had been used to predict flowering time based on day length and temperature. Hall et al. (2012) also indicated that the photoperiod inductive phase of hemp is jointly influenced by both air temperature and photoperiod. In our study, growing conditions including air temperature and nutrient fertility are nearly identical in each environmentally controlled room and thus did not contribute to differences in plant flowering performances. Flowering response, as recorded in this study, was therefore free from the confounding influence of temperature and nutrient deficiency (excluding Expt. 4) and thus provides an enhanced foundational understanding of relationships between photoperiod and flowering response in hemp.

Collectively, based upon study findings and available literature, we believe the hemp juvenile phase to be controlled by genetics rather than photoperiod or temperature. The pre-flowering of the single sex-indicating flower at the axillary is photo insensitive. The response to photoperiod from preflowering to flowering at the apical meristem is affected by both photoperiod and temperature and can be either quantitative (most cultivars) or day-neutral (such as 'CFX-1', 'Joey', 'Tygra', and 'Helena'), dependent upon cultivar.

\section{Extension Growth}

480

Generally, plant height increased as day length increased as would be expected from increased photosynthesis. Plant height extension growth was 47 to $102 \%$ greater under $14 \mathrm{~h}$ day length compared to the $12 \mathrm{~h}$, control group in nine essential oil cultivars, while the imposed photoperiods did not affect the remaining six cultivars (Fig. 2). The longer stem could have resulted from a longer vegetative stage caused by the delay in floral initiation, which has been reported on a variety of crops (Craig and Runkle, 2013; Zhang and Runkle, 2019). Under certain photoperiod treatments, flowering was delayed but the height extension growth was not affected; this included 'Cherry Wine-BS', 'Cherry Wine-CC', and 'Wife-CC' under $13 \mathrm{~h}$, 'ACDC-CC' under $13 \mathrm{~h} 30 \mathrm{~min}$, 'ACDC-AC' and 'Cherry*T1-BS' under 13 h 45 min, and 'Cherry-CC' under both 13 h 30 min and 13 h 45 min (Fig. 3 and Supplementary fig. 1). Results indicated flowering initiation of essential oil hemp was more sensitive than extension growth in response to photoperiods. In addition, unlike flowering, extension growth of essential oil cultivars with the same name but from different sources generally responded similarly, except "Cherry Wine". Campbell et al. (2019) indicated that plant height was collectively 
influenced by both environment (e.g. irrigation) and genetics, accounting for $38 \%$ and $36 \%$ of variance, respectively. We concluded that similar height extension growth among essential oil cultivars under different treatments was due to similar irrigation applications.

In contrast to essential oil cultivars, extension growth of fiber/grain cultivars was not affected by photoperiod, except 'CFX-1' and 'HAN-NE' (Supplementary Fig. 3). Height extension of 'HAN$\mathrm{NE}$ ' was 58 to $64 \%$ greater when day length exceeds $14 \mathrm{~h}$ due to the later flower initiation development. Interestingly, stem extension of 'CFX-1' was shorter under $18 \mathrm{~h}$ photoperiod compared to $13 \mathrm{~h} 30 \mathrm{~min}$. We believe ' $\mathrm{CFX}-1$ ' is photo insensitive and this difference was caused by individual variances.

\section{Sex}

Plant sex was recorded and calculated across the lighting treatments for fiber/grain hemp cultivars (Table 2). Among all the fiber/grain hemp cultivars tested, most cultivars had a relatively equal proportion of male and female plants in general with a small occurrence of monecious plant development, which is consistent with Hall et al. (2012). 'Tygra' had the highest proportion of monecious plants $(55.7 \%)$ with a small proportion of female plant development $(4.3 \%)$. 'Helena' was one-third monecious. Most of ' $\mathrm{CFX}-1$ ' were female plants with no monecious plants that developed. The sex of more than $25 \%$ of 'HAN-NE', 'HAN-NW', 'PUMA-3', and 'PUMA-4' could not be determined due to a lack of flowering response throughout the duration of our experiment.

512 Overall, flowering of female and monecious plants was delayed by 1-2 d compared to male plants 513 (Fig. 3). Our observations were supported by Borthwick and Scully's (1954) findings where greater flowering delay occurred in male plants when compared to female plants under long photoperiods. Hall et al. (2012) and van der Werf et al. (1994) suggested that extending day length would alter the sex proportion of flowering hemp plants and that male and monoecious plants would fail to flower when photoperiod exceeded the optimal day length. Additionally, Werf et al. (1994) suggested that unlike male hemp plants, female flowering would be less influenced by photoperiod. We did not observe such trends in fiber hemp cultivars and no flowering pattern or changes in flowering percentage were identified when photoperiod exceeded the optimal $14 \mathrm{~h}$ (Supplementary Table). Female hemp also has a significantly shorter extension growth than male and monecious plants at

522 flowering (Fig. 3).

\section{CONCLUSION}

This research reported flowering and growth of 27 hemp cultivars in response to different photoperiods under both indoor controlled and outdoor natural environments. Pre-flowering of hemp is photo insensitive, but the response to photoperiod from pre-flowering to flowering can be either quantitative or day neutral. Depending on photosensitivity, a photoperiod difference as little as 15 min significantly influenced floral initiation of some essential oil cultivars. Northern fiber/grain hemp cultivars had a shorter juvenile phase and faster flowering than cultivars from southern latitudes. Cultivar name may not be enough to finely estimate photoperiod response for essential oil cultivars. Flowering performance of hemp appears to be influenced by civil twilight and thus this 
534

535

536

537

538

539

540

541

542

543

544

545

546

547

548

549

550

551

552

553

554

555

556

557

558

559

560

561

562

563

564

565

566

567

568

569

response. Male plants flower faster than female and monecious plants. Plant height generally increased as the day length increased in essential oil cultivars but not in fiber/grain cultivars.

\section{SUPPORTING INFORMATION}

S1 Table. Germplasm source, types, and referred name for fifteen essential oil hemp cultivars.

S2 Table. Means ( \pm SE) of controlled rooms air temperature, relative humidity, and photosynthetic photon flux density (PPFD) of photoperiod treatments for essential oil, fiber, and grain cultivars in Expt. 1, 2, 3, and 4 as measured by thermocouples and quantum sensors. Light intensity was measure at ten representative positions at plant canopy level at the onset of each growing stage while air temperature and relative humidity were recorded by a wireless data logger throughout the growing stages.

S1 Figure. Days to flower (A) and height extension growth at flowering (B) of five essential oil cultivars in Expt. 1. All data were pooled from ten replications except 'JL Baux-CC' (eight replications). NS indicates insignificant treatment effects. NA indicates the majority of the 10 replicates (i.e. 6/10) were reported as not flowering. Means sharing a letter are not statistically different by Tukey's HSD test at $\mathrm{P} \leq 0.05$. Error bars indicate standard error.

S2 Figure. Days to flower of twelve fiber/grain hemp cultivars in Expt. 3. All data were pooled from multiple replications as described in the Methods. NS indicates insignificant treatment effects. NA indicates the less than three plants were reported as not flowering. Means sharing a letter are not statistically different by Tukey's HSD test at $\mathrm{P} \leq 0.05$. Error bars indicate standard error.

S3 Figure. Height extension growth at flowering of twelve fiber/grain hemp cultivars in Expt. 3. All data were pooled from multiple replications as described in the Methods. NS indicates insignificant treatment effects. NA indicates the less than three plants were reported as not flowering. Means sharing a letter are not statistically different by Tukey's HSD test at $\mathrm{P} \leq 0.05$. Error bars indicate standard error.

\section{ACKNOWLEDGEMENT}

We would like to acknowledge Brandon White and Chris Halliday for their technical support; James Johnston and Dillan Raab for their hard work and effort maintaining experimental plants and collecting phenotypic data; Jerry Fankhauser and Sandra Alomar for administrative assistance; Green Point Research, ANO CBD, and Green Roads for donating the cultivars used in this research; and all members of the University of Florida IFAS Industrial Hemp Pilot Project for their collaboration.

\section{FUNDING}

This project was made possible by financial support from Green Roads LLC, Roseville Farms LLC, and the Florida Agricultural Experiment Station. 


\section{AUTHOR CONTRIBUTIONS}

572 MZ: conceptualization, data curation, formal analysis, investigation, methodology, original draft,

review and editing (lead), supervision, validation, visualization.

574 SA: conceptualization, data curation, formal analysis, investigation, methodology, supervision,

validation, visualization, review and editing (supporting).

ZB: funding acquisition, project administration, supervision, resources, review and editing

577 (supporting).

BP: conceptualization, methodology, project administration, supervision, resources, review and editing (supporting).

580

581

582

583

584

585

586

587

588

589

590

591

592

593

594

595

596

597

598

599

600

601

602

603

604

605

\section{CONFLICT OF INTEREST}

The authors declare that the research was conducted in the absence of any commercial or financial relationships that could be construed as a potential conflict of interest.

\section{REFERENCES}

Amaducci, S., Colauzzi, M., Bellocchi, G., and Venturi, G. (2008). Modelling post-emergent hemp phenology (Cannabis sativa L.): Theory and evaluation. European Journal of Agronomy. 28, 90-102.

Amaducci, S., Colauzzi, M., Bellocchi, G., Cosentino, S.L., Pahkala, K., Stomph, T.J., Westerhuis, W., Zatta, A., and Venturi, G. (2012). Evaluation of a phenological model for strategic decisions for hemp (Cannabis Sativa L.) biomass production across European sites. Industrial Crops and Products. 37, 100-110.

Anderson, E., Baas, D., Thelen, M., Burns, E., Chilvers, M., Thelen, K., DiFonzo, C., and Wilke, B. (2019). Industrial Hemp Production in Michigan. https://www.canr.msu.edu/hemp/uploads/files/industrialhempinfosheet_2019-05-24.pdf [Accessed February 20, 2021]

Borthwick, H.A., and Scully, N.J. (1954). Photoperiodic responses of hemp. Botanical Gazette. 116, 14-29.

Campbell, B.J., Berrada, A.F., Hudalla, C., Amaducci, S., and McKay, J.K. (2019). Genotypex environment interactions of industrial hemp cultivars highlight diverse responses to environmental factors. Agrosystems, Geosciences and Environment. 2, 1-11.

Cherney, J. H., and Small, E. (2016). Industrial hemp in North America: Production, politics and potential. Agronomy. 6, 58.

Cho, L.H., Yoon, J., and An, G. (2017). The control of flowering time by environmental factors. The Plant Journal. 90, 708-719. 
Congressional Research Service (2019). Defining Hemp: A Fact Sheet. https://www.everycrsreport.com/files/20190322_R44742_1b0195c6aa7e2cad29256c85a8574 347c1ee833d.pdf [Accessed October 18, 2020]

Cosentino, S.L., Testa, G., Scordia, D., and Copani, V. (2012). Sowing time and prediction of flowering of different hemp (Cannabis sativa L.) genotypes in southern Europe. Industrial Crops and Products. 37, 20-33.

Craig, D.S., and Runkle, E.S. (2013). A moderate to high red to far-red light ratio from light-emitting diodes controls flowering of short-day plants. Journal of the American Society for Horticultural Science. 138, 167-172.

614

615

Green, G. (2017). The Cannabis Grow Bible. 3rd ed. Green Candy Press.

616

617

Hall, J., Bhattarai, S.P., and Midmore, D.J. (2012). Review of flowering control in industrial hemp.

618 Journal of Natural Fibers. 9, 23-36.

619

Hall, J., Bhattarai, S.P., and Midmore, D.J. (2014). Effect of industrial hemp (Cannabis sativa L.) planting density on weed suppression, crop growth, physiological responses, and fibre yield in the subtropics. Renewable Bioresources. 2, 1-7.

Heslop-Harrison, J., and Heslop-Harrison, Y. (1969). Cannabis sativa L. The induction of flowering. Some case studies. MacMillan Co. Pty. Ltd.

Heslop-Harrison, J., and Heslop-Harrison, Y. (1972). Sexuality of Angiosperms. Physiology of development: from seeds to sexuality. New York: Academic Press.

Jung, C., and Müller, A.E. (2009). Flowering time control and applications in plant breeding. Trends in plant science. $14,563-573$.

Kishida, Y.A.S.U.M.I.T.S.U. (1989). Changes in light intensity at twilight and estimation of the biological photoperiod. Japan Agr Res Q. 22, 247-252.

632

633

634

Lane, H.C., Cathey, M., and Evans, L.T. (1965). The dependence of flowering in several long-day plants on the spectral composition of light extending the photoperiod. Amer. J. Bot. 52, 10061014.

Lisson, S.N., Mendham, N.J., and Carberry, P.S. (2000). Development of a hemp (Cannabis sativa L.) simulation model 2. The flowering response of two hemp cultivars to photoperiod. Australian Journal of Experimental Agriculture. 40, 413-417. growth stages of hemp (Cannabis sativa L.). Journal of the international hemp association. 5, 65.

Moher, M., Jones, M., and Zheng, Y. (2020). Photoperiodic response of in vitro Cannabis sativa plants. HortScience. 56, 108-113.

Navarro, J.A.R., Willcox, M., Burgueño, J., Romay, C., Swarts, K., Trachsel, S., Preciado, E., Terron, A., Delgado, H.V., Vidal, V., and Ortega, A. (2017). A study of allelic diversity underlying flowering-time adaptation in maize landraces. Nature genetics. 49, 476-480.

Potter, D.J. (2014). Cannabis horticulture. Handbook of Cannabis. 
Runkle, E.S., Heins, R.D., Cameron, A.C., and Carlson, W.H. (1998). Flowering of herbaceous perennials under various night interruption and cyclic lighting treatments. HortScience. 33, 672-677.

Salisbury, F.B. (1981). Twilight effect: initiating dark measurement in photoperiodism of Xanthium. Plant Physiology. 67, 1230-1238.

Sawler, J., Stout, J.M., Gardner, K.M., Hudson, D., Vidmar, J., Butler, L., Page, J.E., and Myles, S. (2015). The genetic structure of marijuana and hemp. PloS one. 10, e0133292.

Sengloung, T., Kaveeta, L., and Nanakorn, W. (2009). Effect of sowing date on growth and development of Thai hemp (Cannabis sativa L.). Kasetsart Journal. 43, 423-431.

Small, E. (2015). Evolution and classification of Cannabis sativa (marijuana, hemp) in relation to human utilization. The botanical review. 81, 189-294.

Spitzer-Rimon, B., Duchin, S., Bernstein, N., and Kamenetsky, R. (2019). Architecture and florogenesis in female Cannabis sativa plants. Frontiers in plant science. 10, 350.

Takimoto, A.T.S.U.S.H.I. and IKEDA, K. (1961). Effect of twilight on photoperiodic induction in some short day plants. Plant and Cell Physiology. 2.

Van der Werf, H.M.G, Haasken, H.J., Wijlhuizen, M. (1994). The effect of daylength on yield and quality of fibre hemp (Cannabis sativa L.). European Journal of Agronomy. 3, 117-123.

Vince-Prue, D. and Canham, A. (1983). Horticultural significance of photmorphogenesis. Photomorphogenesis. Springer-Verlag, Heidelberg.

Williams, A. (2020). Hemp Breeding and the Uses of Photoperiod Manipulation.

Zhang, M., and Runkle, E.S. (2019). Regulating flowering and extension growth of poinsettia using red and far-red light-emitting diodes for end-of-day lighting. HortScience. 54, 323-327.

Zhang, Q., Chen, X., Guo, H., Trindade, L.M., Salentijn, E.M., Guo, R., Guo, M., Xu, Y., and Yang, M. (2018). Latitudinal adaptation and genetic insights into the origins of Cannabis sativa L. Frontiers

in

plant

science. 9 ,

1876. 


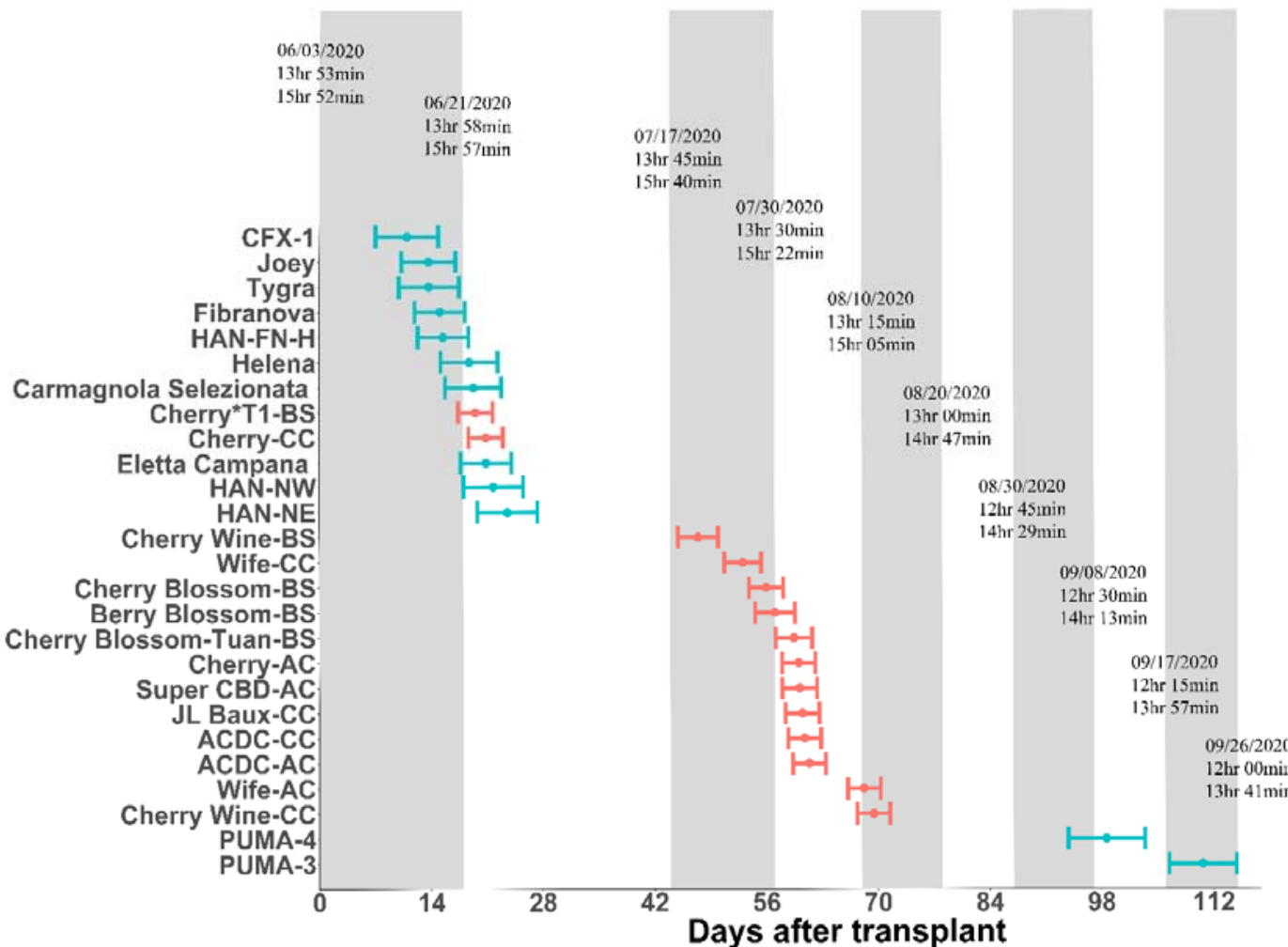

Hemp Type - Essential oil

673 Figure 1. Flowering date of essential oil, grain, and fiber cultivars after transplanting from 674 greenhouse to field conditions on June $3^{\text {rd }}, 2020$. Points depict genetic means and error bars represent $67595 \%$ confidence intervals. Floating text depicts date of $15 \mathrm{~min}$ daylength intervals (top), sunrise to 676 sunset daylengths (middle), and civil twilight lengths (bottom). 

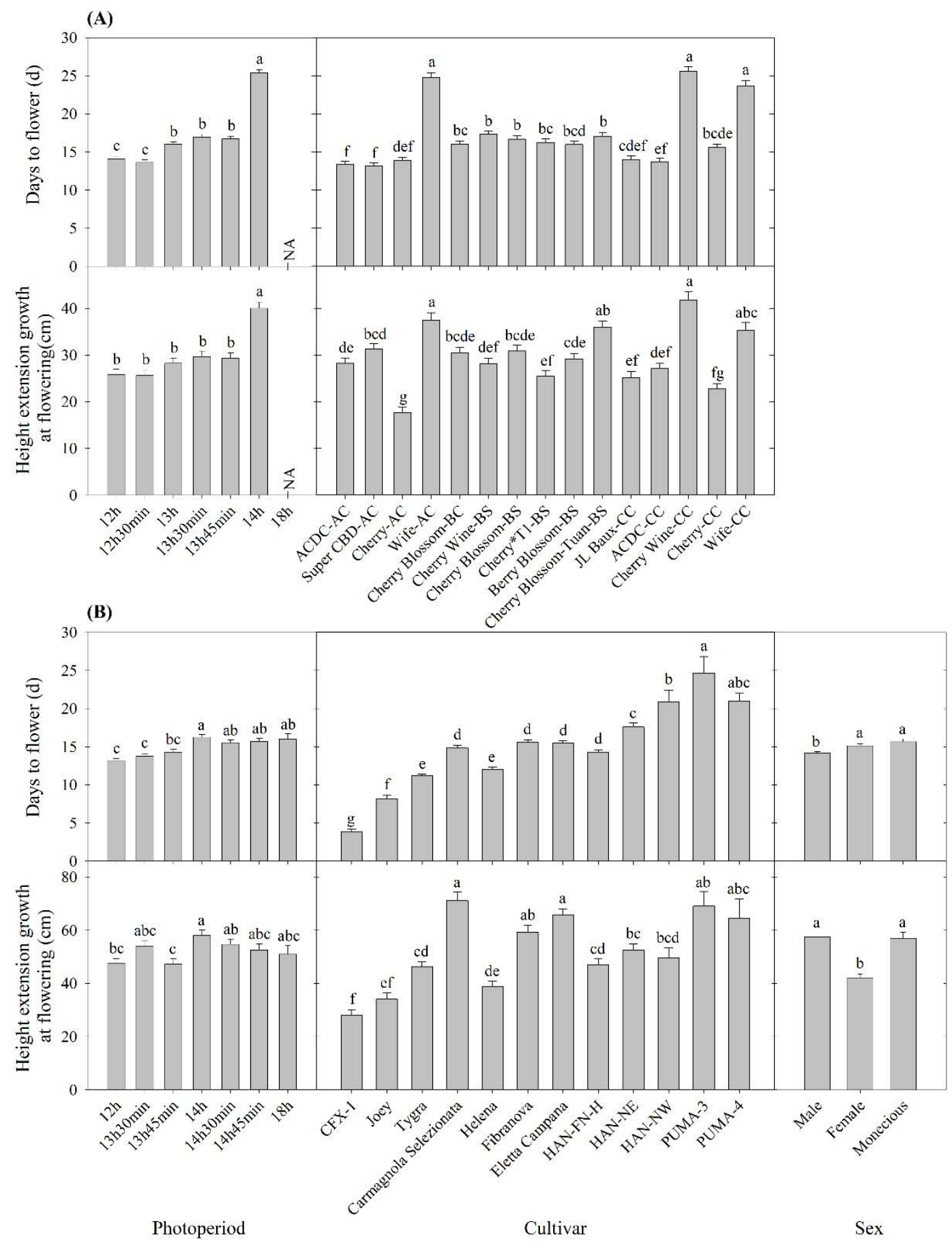

678 Figure 2. Days to flower after lighting treatment initiated and height extension growth at flowering
679 of (A) essential oil and (B) fiber/grain cultivars under different photoperiods, cultivars, and/or sex 680 from Expt. 1 and 2. Means sharing a letter are not statistically different by Tukey's HSD test at P $\leq$ 681 0.05 .

Error bars indicate standard error. 


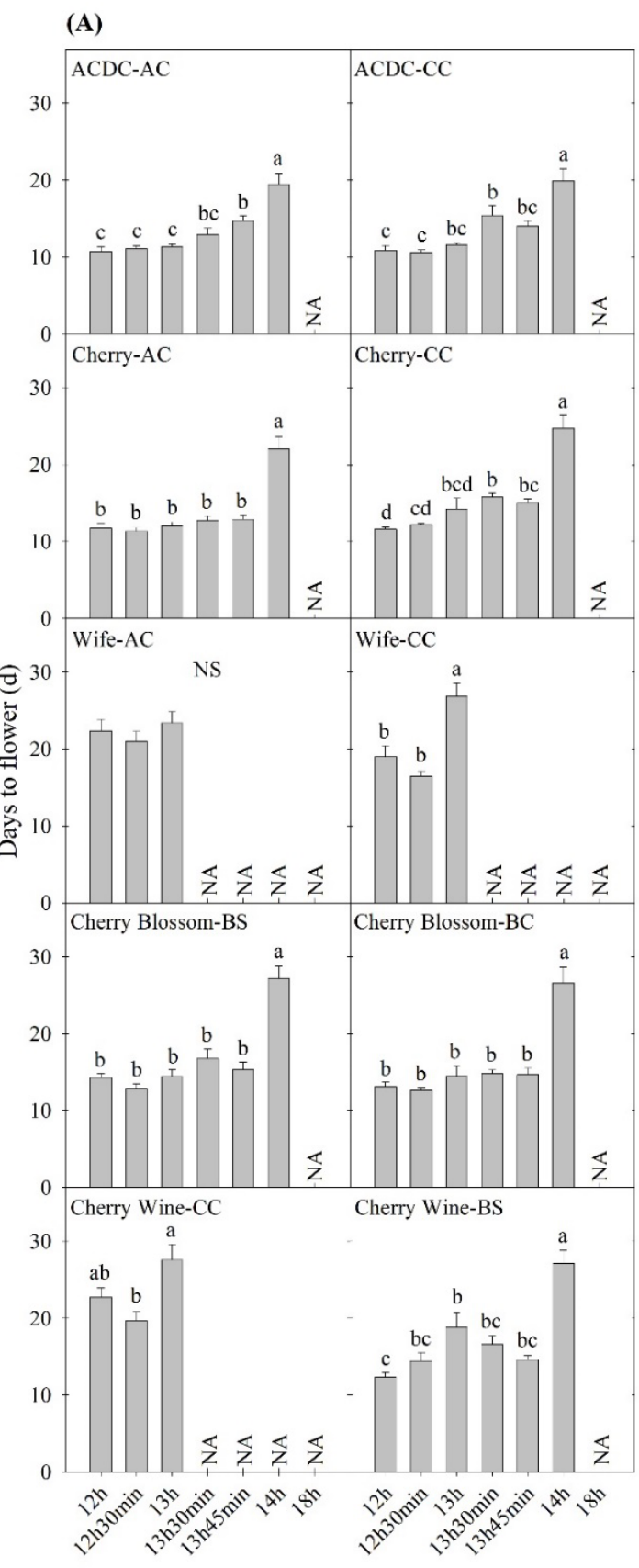

Treatment
(B)

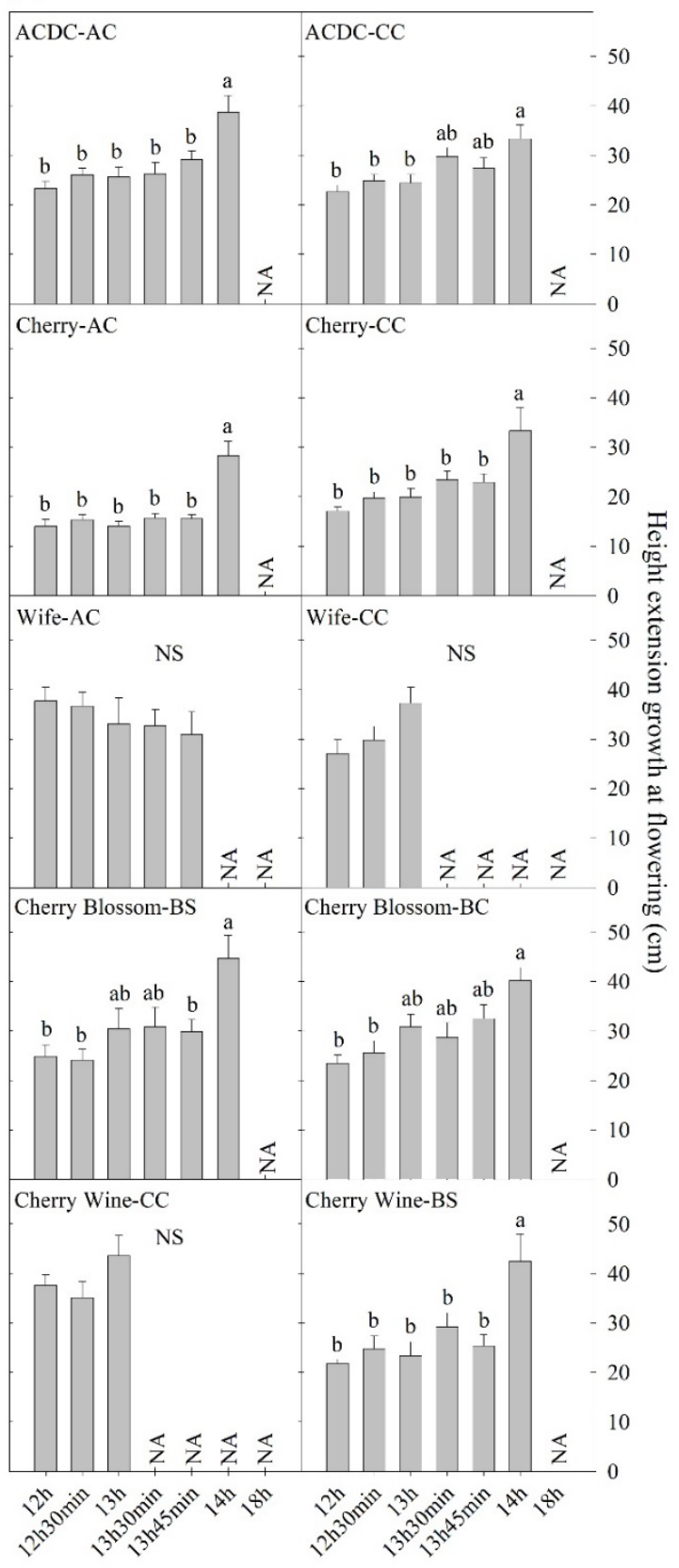

Treatment

683 Figure 3. Comparison of (A) days to flower and (B) height extension growth at flowering of ten 684 essential oil cultivars with same name but different sources in Expt. 1. All data were pooled from ten 685 replications except 'ACDC-AC' $(n=9)$. NS indicates insignificant treatment effects. NA indicates the 686 majority of the 10 replicates (i.e. 6/10) were reported as not flowering. Means sharing a letter are not 687 statistically different by Tukey' $\mathrm{s}$ HSD test at $\mathrm{P} \leq 0.05$. Error bars indicate standard error. 
688 Table 1. Flowering percentage of CBD and fiber hemp from Expt. 1, 2 and 3. The Boolean evaluation was conducted at week 5 of flowering

689 after the treatment initiation excluding dead plants.

\begin{tabular}{|c|c|c|c|c|c|c|c|c|c|c|c|c|}
\hline \multirow[b]{2}{*}{ Cultivar } & \multicolumn{11}{|c|}{ Treatments } & \multirow{2}{*}{$\begin{array}{c}\text { Critical } \\
\text { Photoperiod }\end{array}$} \\
\hline & $18 \mathrm{~h}$ & $15 \mathrm{~h} 30 \mathrm{~min}$ & $15 \mathrm{~h}$ & $14 \mathrm{~h} 45 \mathrm{~min}$ & $14 \mathrm{~h} 30 \mathrm{~min}$ & $14 \mathrm{~h}$ & $13 \mathrm{~h} 45 \mathrm{~min}$ & $13 \mathrm{~h} 30 \mathrm{~min}$ & $13 \mathrm{~h}$ & $12 \mathrm{~h} 30 \mathrm{~min}$ & $12 \mathrm{~h}$ & \\
\hline & \multicolumn{12}{|c|}{ CBD cultivars } \\
\hline ACDC-AC & $0 \%$ & $40 \% *$ & $100 \% *$ & $100 \% *$ & $100 \% *$ & $100 \%$ & $100 \%$ & $100 \%$ & $100 \%$ & $100 \%$ & $100 \%$ & $\square 15 \mathrm{~h}$ \\
\hline Super CBD-AC & $0 \%$ & $0 \% *$ & $0 \% *$ & $100 \% *$ & $100 \% *$ & $100 \%$ & $100 \%$ & $100 \%$ & $100 \%$ & $100 \%$ & $100 \%$ & $14 \mathrm{~h} 45 \mathrm{~min}-15$ \\
\hline Cherry-AC & $0 \%$ & $0 \% *$ & $20 \% *$ & $100 \% *$ & $100 \% *$ & $80 \%$ & $100 \%$ & $100 \%$ & $100 \%$ & $100 \%$ & $100 \%$ & $15 h-15 h 30 m$ \\
\hline Wife-AC & $0 \%$ & - & - & - & - & $10 \%$ & $20 \%$ & $22 \%$ & $80 \%$ & $100 \%$ & $100 \%$ & $\square 14 \mathrm{~h}$ 旁产 \\
\hline Cherry Blossom-BC & $0 \%$ & $0 \% *$ & $0 \% *$ & $80 \% *$ & $100 \% *$ & $70 \%$ & $90 \%$ & $100 \%$ & $100 \%$ & $100 \%$ & $100 \%$ & $14 \mathrm{~h} 45 \mathrm{~min}$ - 䵿 \\
\hline Cherry Wine-BS & $0 \%$ & - & - & $100 \% *$ & $100 \% *$ & $70 \%$ & $89 \%$ & $100 \%$ & $100 \%$ & $100 \%$ & $100 \%$ & $\square$ 14h45mioñ \\
\hline Cherry Blossom-BS & $0 \%$ & $0 \% *$ & $60 \% *$ & $100 \% *$ & $100 \% *$ & $78 \%$ & $100 \%$ & $89 \%$ & $100 \%$ & $100 \%$ & $100 \%$ & $15 \mathrm{~h}-15 \mathrm{~h} 30$ hakn \\
\hline Cherry*T1-BS & $0 \%$ & - & - & $100 \% *$ & $100 \% *$ & $43 \%$ & $100 \%$ & $90 \%$ & $100 \%$ & $100 \%$ & $100 \%$ & $\square 14 \mathrm{~h} 45 \mathrm{mi}$ \\
\hline Berry Blossom-BS & $0 \%$ & - & - & - & - & $30 \%$ & $80 \%$ & $80 \%$ & $90 \%$ & $100 \%$ & $100 \%$ & $\square 14 \mathrm{~h}$ \\
\hline $\begin{array}{c}\text { Cherry Blossom- } \\
\text { Tuan-BS }\end{array}$ & $0 \%$ & - & - & - & - & $60 \%$ & $90 \%$ & $100 \%$ & $100 \%$ & $100 \%$ & $100 \%$ & $\square 14 \mathrm{~h} \overline{\bar{\Phi}}$ \\
\hline JL Baux-CC & $0 \%$ & $60 \% *$ & $100 \% *$ & $100 \% *$ & $100 \% *$ & $100 \%$ & $88 \%$ & $100 \%$ & $100 \%$ & $100 \%$ & $100 \%$ & $\square 15 \mathrm{~h} 30 \mathrm{~min}$ \\
\hline ACDC-CC & $0 \%$ & $0 \% *$ & $100 \% *$ & $100 \% *$ & $100 \% *$ & $100 \%$ & $100 \%$ & $100 \%$ & $100 \%$ & $100 \%$ & $100 \%$ & $15 \mathrm{~h}-15 \mathrm{~h} 30 \mathrm{~m}$ \\
\hline Cherry Wine-CC & $0 \%$ & - & - & - & - & $0 \%$ & $60 \%$ & $50 \%$ & $70 \%$ & $100 \%$ & $100 \%$ & 13h45min - 14 \\
\hline Cherry-CC & $0 \%$ & $0 \% *$ & $100 \% *$ & $100 \% *$ & $100 \% *$ & $80 \%$ & $100 \%$ & $100 \%$ & $100 \%$ & $100 \%$ & $100 \%$ & $15 \mathrm{~h}-15 \mathrm{~h} 30 \mathrm{mi}$ \\
\hline \multirow[t]{2}{*}{ Wife-CC } & $0 \%$ & - & - & - & 一 & $30 \%$ & $60 \%$ & $50 \%$ & $90 \%$ & $100 \%$ & $100 \%$ & $\square 14 \mathrm{~h}$ \\
\hline & \multicolumn{12}{|c|}{ Fiber/Grain cultivars } \\
\hline CFX-1 & $100 \%$ & - & - & $100 \%$ & $100 \%$ & $100 \%$ & $100 \%$ & $100 \%$ & - & - & $100 \%$ & $\square 18 \mathrm{~h}$ or $\mathrm{DN}^{\overline{\underline{z}}}$ \\
\hline Joey & $100 \%$ & - & - & $100 \%$ & $100 \%$ & $100 \%$ & $100 \%$ & $100 \%$ & - & - & $100 \%$ & $\square 18 \mathrm{~h}$ or $\mathrm{DN}$ \\
\hline
\end{tabular}




\section{Flowering response of industrial hemp}

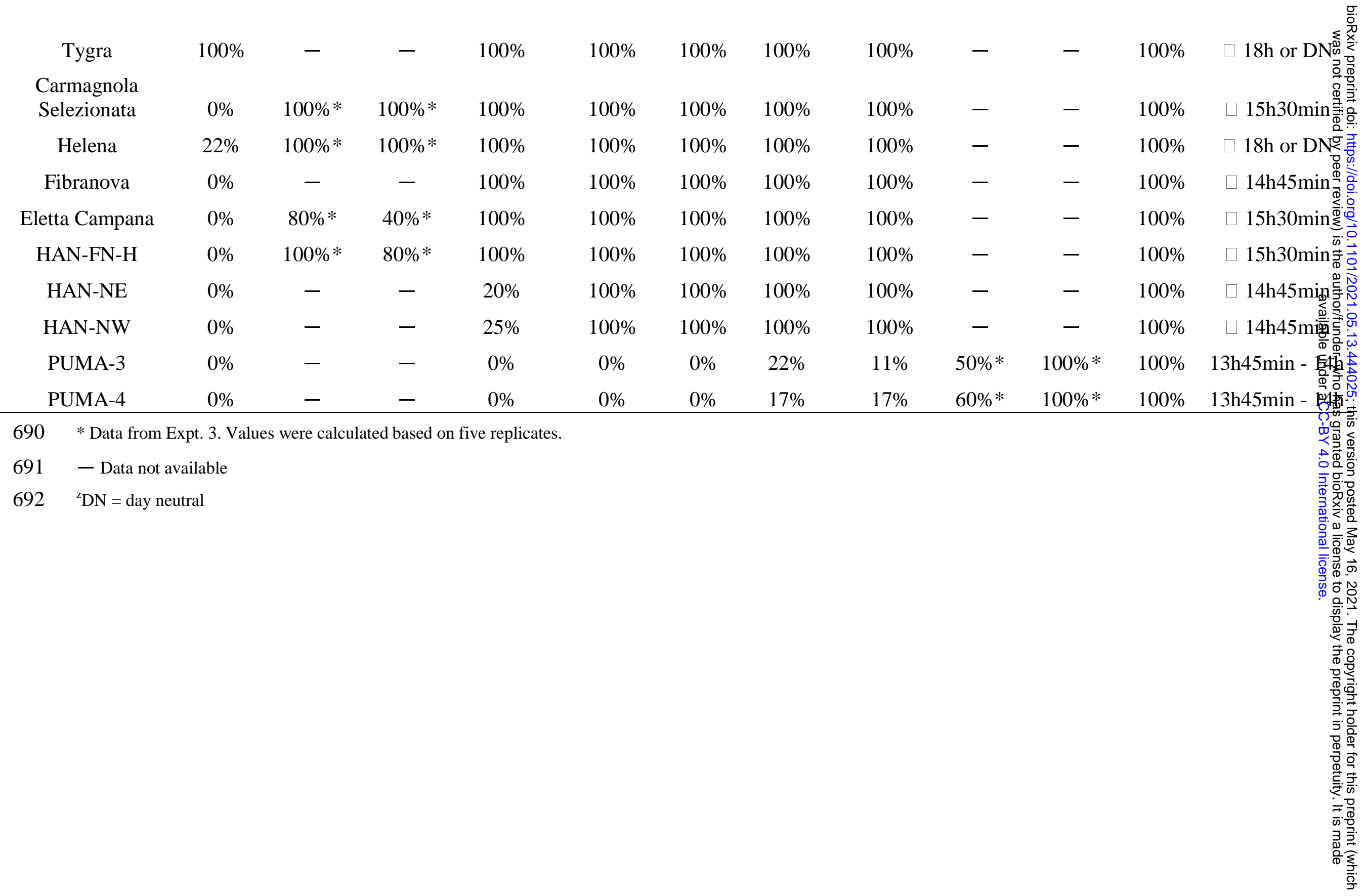


693 Table 2. Origin and sex status of fiber/grain hemp cultivars in Expt. 2.

\begin{tabular}{cccccc}
\hline Cultivar & Origins & Male & Female & Monecious & Unknown \\
\hline CFX-1 & Canadian & $17.1 \%$ & $82.9 \%$ & $0.0 \%$ & $0.0 \%$ \\
Joey & Canadian & $45.7 \%$ & $34.8 \%$ & $19.5 \%$ & $0.0 \%$ \\
Tygra & Poland & $40.0 \%$ & $4.3 \%$ & $55.7 \%$ & $0.0 \%$ \\
Carmagnola Selezionata & Southern European & $48.1 \%$ & $33.3 \%$ & $3.7 \%$ & $14.9 \%$ \\
Helena & Southern European & $50.7 \%$ & $10.2 \%$ & $33.3 \%$ & $5.8 \%$ \\
Fibranova & Southern European & $32.7 \%$ & $46.9 \%$ & $6.1 \%$ & $14.3 \%$ \\
Eletta Campana & Southern European & $35.7 \%$ & $47.1 \%$ & $2.9 \%$ & $14.3 \%$ \\
HAN-FN-H & Northern Chinese & $32.8 \%$ & $48.6 \%$ & $4.3 \%$ & $14.3 \%$ \\
HAN-NE & Central Chinese & $37.1 \%$ & $37.1 \%$ & $0.0 \%$ & $25.8 \%$ \\
HAN-NW & Central Chinese & $25.0 \%$ & $50.0 \%$ & $0.0 \%$ & $25.0 \%$ \\
PUMA-3 & Southern Chinese & $14.3 \%$ & $7.9 \%$ & $1.6 \%$ & $76.2 \%$ \\
PUMA-4 & Southern Chinese & $7.3 \%$ & $12.2 \%$ & $0.0 \%$ & $80.5 \%$ \\
\hline
\end{tabular}

